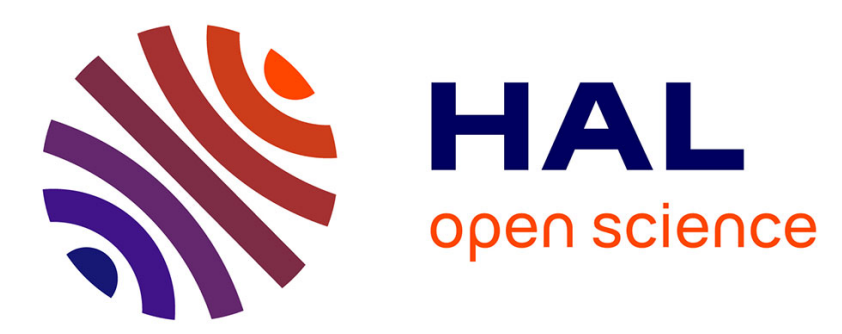

\title{
Immunohistochemical evidence of a melanopsin cone in human retina.
}

Ouria Dkhissi-Benyahya, Camille Rieux, Roelof A. Hut, Howard M. Cooper

\section{To cite this version:}

Ouria Dkhissi-Benyahya, Camille Rieux, Roelof A. Hut, Howard M. Cooper. Immunohistochemical evidence of a melanopsin cone in human retina.. Investigative Ophthalmology \& Visual Science, 2006, 47 (4), pp.1636-41. 10.1167/iovs.05-1459 . inserm-00131429

\section{HAL Id: inserm-00131429 https://www.hal.inserm.fr/inserm-00131429}

Submitted on 4 Sep 2009

HAL is a multi-disciplinary open access archive for the deposit and dissemination of scientific research documents, whether they are published or not. The documents may come from teaching and research institutions in France or abroad, or from public or private research centers.
L'archive ouverte pluridisciplinaire HAL, est destinée au dépôt et à la diffusion de documents scientifiques de niveau recherche, publiés ou non, émanant des établissements d'enseignement et de recherche français ou étrangers, des laboratoires publics ou privés. 


\section{Immunohistochemical evidence of a melanopsin cone in human retina}

Ouria Dkhissi-Benyahya ${ }^{1,2}$, Camille Rieux ${ }^{1,2}$, Roelof A. Hut ${ }^{1,3}$, and Howard M. Cooper ${ }^{1,2}$

${ }^{1}$ INSERM U371, Cerveau et Vision, Department of Chronobiology, 18 Avenue du Doyen Lépine, Bron, France

${ }^{2}$ IFR19, UCBL1, Lyon, France

${ }^{3}$ Present address: University of Groningen, Animal Behaviour, 9750 AA, The Netherlands.

Abbreviated Title: Human Melanopsin cone

Manuscript word count:2952; number of pages: 20; number of figures: 3

\section{Corresponding Author :}

Dr Howard Cooper

INSERM U371

Cerveau et Vision

18 Avenue Du Doyen Lépine

69675 Bron, France

tel. 33-472.91.34.69 / fax. 33-472.91.34.61

cooper@lyon.inserm.fr

Key words : photoreceptor; cone; melanopsin; opsin; circadian system; visual system 


\section{Abstract}

Purpose: Melanopsin is expressed in a subset of intrinsically photosensitive ganglion cells that project to the suprachiasmatic nucleus (SCN) which are involved in the photic entrainment of circadian rhythms and other non image forming functions (pupil light reflex, masking, acute heart rate response, alertness). Melanopsin has recently been shown to be a "bireactive" photopigment which functions as a photosensory opsin using 11-cis retinaldehyde as a chromophore and has intrinsic photoisomerase activity. Melanopsin is widely distributed in the retina of vertebrates and depending on the species, is expressed in ganglion, amacrine, horizontal, and photoreceptor cells. The present study was conducted to determine the distribution of this opsin in the human retina.

Methods: Human eyes were obtained from donors and fixed shortly after death (Department of Anatomy, University of Lyon, UCBL1) under approval of the Institutional Human Subjects Committee. Immunohistochemistry was used to determine melanopsin expression in the retinas of 3 donors. The possible co-expression of this photopigment with other opsins was studied by double-labelling immunocytochemistry and confocal analysis.

Results: The present study in the human retina shows that in addition to the expected labelling in ganglion cells of the inner retinal layers, an unexpected finding shows melanopsin immunopositive label in the outer segments of cones that do not co-express other known opsins. These melanopsin expressing cones are extremely sparse $\left(5-25\right.$ cones $/ \mathrm{mm}^{2} ; 0.1-0.5 \%$ of the entire cone population) and are located in the peripheral retina.

Conclusions: The presence of melanopsin in human cones suggests an image and non image forming roles in visual responses at both the cone input and ganglion cell output stages and their involvement in a broad spectrum of irradiance detection functions in the visual system. 


\section{Introduction}

Several novel-opsins mediating non visual responses have been identified in cells and tissues other than the classical retinal photoreceptors in a number of vertebrate species. These photopigments include pinopsin in chicken, vertebrate ancient opsin in salmon and zebrafish, encephalopsin and neuropsin in mice and humans, and melanopsin in Xenopus and mammals. Among these photopigments, only neuropsin and melanopsin have been described in the retina of mammals including humans ${ }^{1}$.

Melanopsin (Opn4), an opsin based photopigment originally cloned from amphibian melanophores ${ }^{2}$, is expressed in the retina of many vertebrate species. In rodents and primates, melanopsin is expressed in a subset of retinal ganglion cells that are intrinsically photosensitive ${ }^{3 \text {, }}$ ${ }^{4}$. The action spectrum of these ganglion cells is typical of an opsin-based photopigment peaking near $480 \mathrm{~nm}$. In rodents, melanopsin-positive cells are uniformly distributed throughout the ganglion cell layer with a few displaced ganglion or amacrine cells in the inner nuclear layer ${ }^{5-7}$. The majority of ganglion cells that express melanopsin project to the suprachiasmatic nucleus or SCN and also express the neuropeptide pituitary adenylate cyclase activating peptide, PACAP ${ }^{7}$. Melanopsin participates significantly in several circadian and non-visual responses to light including photic entrainment of the circadian system, pupillary light reflex, masking responses and photic induction of FOS in the SCN ${ }^{8-11}$. In mice that lack melanopsin, the amplitude of a light-induced phase shift, masking and pupillary responses are reduced ${ }^{8,9,11}$. Triple knockout mice with targeted deletion of the melanopsin gene and non functional rod-cone transduction pathway display a complete loss of photic entrainment, pupillary light response, masking and arylalkylamine- $\mathrm{N}$-acetyltransferase suppression by light 12,13 , demonstrating that other photopigments are not involved in these responses. Electrophysiological and ultrastructural evidence in rodents show that melanopsin-expressing ganglion cells receive excitatory bipolar 
and inhibitory amacrine cell inputs suggesting that their intrinsic photic response can be modified by rod and/or cone signals ${ }^{3,14}$. In primates, a recent electrophysiological study shows that SW cones provide an inhibitory input to melanopsin-containing ganglion cells, whereas rods and MW/LW cones supply an excitatory input ${ }^{4}$.

In humans, melanopsin has been cloned and the messenger RNA is highly expressed in the retina with trace amounts detected in the retinal pigment epithelium ${ }^{15}$. A recent study using in situ hybridization and immunohistochemistry demonstrated that the subset of retinal ganglion cells that express melanopsin is uniformly distributed ${ }^{16}$ and co-express PACAP ${ }^{17}$.

There has been considerable debate concerning whether melanopsin has an intrinsic photo-isomerase activity or acts as a photosensory opsin using 11-cis retinaldehyde as a chromophore. Recent evidence form several groups using different heterologous expression systems suggests that melanopsin is bireactive and can use both biochemical mechanisms ${ }^{18-20}$. When incubated with 11-cis retinaldehyde, the action spectrum shows an opsin-based nomogram with a peak around $480 \mathrm{~nm}$, which is similar to that obtained from studies of pupillary reflex, light entrainment of circadian rhythms and more specifically, for electrophysiological recordings from intrinsically melanopsin expressing ganglion cells ${ }^{3,12,21}$.

In the present study, we show that the human retina contains cones which express melanopsin, that are distinct from known short- (SW), mid- (MW), and long-wavelength (LW) cones which form the basis of human trichromatic vision. Together with recent results of biochemical studies showing that this opsin can act as a classical photopigment, the localisation of melanopsin in outer segments supports the idea that these cones constitute functional photoreceptors in humans.

\section{Materials and Methods}


Tissue samples.

All material used in the present study was obtained in compliance with the Declaration of Helsinki for research involving human tissue. Eyes were obtained from 3 donors (Department of Anatomy, University of Lyon, UCBL1), under approval of the Institutional Human Subjects Committee. Donors were of both sexes and varied in age from 40 to 65 years, and had no previous history of eye disease. The eyes, collected 6-18 hours after death, were placed overnight in Zamboni’s fixative (4\% paraformaldehyde with 15\% picric acid in phosphate buffer $0.1 \mathrm{M}, \mathrm{pH}$ 7.4) at $4^{\circ} \mathrm{C}$ and rinsed in phosphate buffer (PBA 0.1 M; sodium azide $0.1 \%$, pH 7.4) the next day. Fixed eyes were cryoprotected by immersion in 30\% sucrose (in PBA) overnight, embedded in a solution of $2.5 \%$ agar with $30 \%$ sucrose and cut on a freezing microtome (Reicher-Jung) at a thickness of $15 \mu \mathrm{m}$. Free-floating retinal sections were placed in titration wells containing PBA and stored until use.

Immunohistochemistry.

Single immuno-labelling using antiserum against the mouse and the human melanopsin ${ }^{5,16}$ and an immuno-peroxidase technique were used to identify melanopsin expressing cells in the human retina. Endogenous peroxidase was first suppressed using a solution of 50\% ethanol in saline with $0.03 \% \mathrm{H}_{2} \mathrm{O}_{2}$. Free floating sections were briefly rinsed in PBS $(0.01 \mathrm{M}, \mathrm{pH} 7.2)$ containing $0.3 \%$ triton and $0.1 \%$ sodium azide (PBSTA) and blocked with 1\%BSA. Sections were incubated in the anti-melanopsin primary antibody (gift from I. Provencio; 1/1200) for 2 days at $4^{\circ} \mathrm{C}$. Immunoreactivity was visualized using a Vectastain ABC Elite kit (PK-6100, Vector Laboratories), followed by incubation in $0.2 \%$ 3,3'-diaminobenzidine-with $0.5 \%$ ammonium nickel sulfate and $0.003 \% \mathrm{H}_{2} \mathrm{O}_{2}$ in tris buffer (0.05M, pH 7.6).

Multiple immunostaining using combinations of anti-opsin antibodies and/or lectin were used to identify melanopsin positive photoreceptors and to study co-expression of melanopsin with other 
cone opsins. To characterize melanopsin positive photoreceptors, we use a biotinylated peanut agglutinin lectin (PNA ,Vector ref. \# B-1075, 1/20) that specifically binds to the extracellular matrix of all cones. In this case, retinal sections were washed twice in PBST and incubated at room temperature for 2 hours in biotinylated PNA (100 mg/ml), which was revealed using FITC avidin D (100 mg/ml, Molecular Probes). To identify SW and MW/LW cone opsins in human retinal sections, we used respectively the mouse monoclonal antibody OS-2 (1/2500) produced against chicken photoreceptor membranes and the mouse monoclonal antibody COS-1 (1/100) generated to chick opsins ${ }^{22}$. Free-floating sections were pre-incubated in PBSTA with $1 \%$ BSA to block nonspecific binding sites. Retinal sections were then incubated in two mixtures of antibodies for melanopsin and either SW or MW/LW opsins. After 4 days of incubation at $4^{\circ} \mathrm{C}$, the binding sites of primary antibodies were demonstrated using a mixture of fluorescent probes, i.e., goat anti-rabbit Alexa 594 (100 mg/ml, Molecular Probes) and goat anti-mouse Alexa 488 (100 mg/ml, Molecular Probes) for 2 hours. Controls were made by omitting primary antibodies or by pre-adsorption of the primary melanopsin antiserum with the immunizing peptide which blocked all labelling. When a mixture of two antibodies or two fluorescent probes were used, a control was done using each antibody singly and also applying them in different sequential order. For example, the pattern of melanopsin and opsin staining were examined in retinal sections when their respective antibodies were used both simultaneously or in succession in different sequences.

Digitized images for single labelling of melanopsin positive neurons were captured using a Spot II camera (Diagnostic Instruments) with 40 and 63X objectives. To verify the presence of double fluorescent label in cones with melanopsin and anti-opsin antibodies, confocal microscopy (Leica TCS SP) was used. Laser lines and emission filters were optimized with the Leica PowerScan software. Confocal images obtained as stacks of images $(0.2 \mu \mathrm{m}$ thickness) were analysed on 
computer (Leica confocal software). Image processing was carried out with Adobe Photoshop software.

\section{Results}

Single immuno-labelling using antiserum against both human and mouse melanopsin and an immuno-peroxidase technique reveals immunopositive ganglion cells and cones in the human retina. In the inner retina, melanopsin is expressed in neurons in the ganglion cell layer (GCL; Fig. 1A) and in the inner nuclear layer (INL; Fig. 1B ) as recently shown in macaque and human 4, 17 . The latter population has been suggested to be composed of displaced ganglion cells or possibly amacrine cells. These two populations of melanopsin-positive cells present a large soma (15-20 $\mu$ m diameter) with dendritic processes localized at the IPL-INL and IPL-GCL borders.

Melanopsin immunopositive photoreceptors were observed using both mouse and human antibodies, with distinct label in the outer segment (Figs. 1C, 1D). These photoreceptors have a typical cone-like morphology and share common features with the other cone types in human retina. Similar to all other human cone opsins - SW, MW and LW - the photopigment melanopsin is only expressed in the outer segment. Second, use of the marker peanut agglutinin lectin (PNA), which is specific to the extracellular matrix of cones, stains all cones including those expressing melanopsin (Fig. 2). These melanopsin-positive photoreceptors were observed in the retina of all 3 donor eyes.

The spatial distribution of the labelled cones differs from that of other cone types since melanopsin positive cones are sparse, evenly distributed and only observed in the peripheral region of the retina, from the parafoveal region (estimated as approximately $20^{\circ}$ from the foveal area) up to approximately $2 \mathrm{~mm}$ from the ora serrata. Retinas from the three subjects were used to quantify the density of melanopsin containing cones. In the 110 retinal sections examined we 
counted a total of 40 immunopositive melanopsin cones (immunoperoxydase and immunofluorescence). This corresponded to a total section length of $98.2 \mathrm{~mm}$ and given the $20 \mu \mathrm{m}$ section thickness, a total retinal surface area of $1.96 \mathrm{~mm}^{2}$. The melanopsin cone density can thus be estimated as 20.4 cones per $\mathrm{mm}^{2}$ of retina. In order to further confirm this density value, the relative numbers of SW to melanopsin expressing cones was compared in sections stained with fluorescent probes for both opsins (40 sections). The counts show a ratio of 1-5 melanopsin positive cones per $100 \mathrm{SW}$ cones. Since in the peripheral regions of the human retina 23, SW cones show an even distribution of 500 cones $/ \mathrm{mm}^{2}$, this yields 5-25 melanopsin cones $/ \mathrm{mm}^{2}$ which is close to the spatial density estimated above. Since Curcio et al. (1990) ${ }^{24}$ has estimated that the mean cone density in the human retina is around 4,500 cones $/ \mathrm{mm}^{2}$, melanopsin immunopositive cones equal $0.11-0.55 \%$ of the entire cone population. This percentage is equivalent to the $0.25 \%$ value estimated for melanopsin expressing ganglion cells vs total ganglion cells in the primate retina ${ }^{4}$.

Since single mammalian cones can express more than one opsin, either during development or at adult stages ${ }^{25,26}$, an important issue was to determine whether melanopsin is expressed uniquely or is co-expressed with other opsins in cone outer segments. We thus used different combinations of double label immunohistochemistry with specific and well characterized monoclonal antibodies against cone photopigments and combined confocal microscopy. Several controls were first made in order to exclude any possible cross-reactions between opsin antibodies in human retina ${ }^{27}$. Figure $3 \mathrm{~A}$ shows and example section of a melanopsin positive cone flanked by several different cones immunopositive for MW/LW opsins. Figure 3B shows a double labelled retinal section with a single melanopsin and a single SWopsin immunopositive cones. In all sections examined, confocal analysis clearly shows that the 
melanopsin-positive cones are distinct and do not contain either SW or MW/LW opsins. No occurrence of co-expression of melanopsin with other cone opsins was ever observed.

\section{Discussion}

Humans and other diurnal primates typically possess three types of cones with sensitivity in the long- (LW, 556-562 nm), medium- (MW, 530-550 nm) and short-wavelength-sensitive range (SW, near 410-435 nm) which allow for trichromatic color vision. In this study we describe a new cone type in the human retina that stains immunopositive for melanopsin and which lacks other known opsins.

This result adds to a wide pattern of neuronal distribution of melanopsin in different retinal cell types among vertebrates. In amphibians, melanopsin is found in ganglion and horizontal cells of the inner retina as well as in iris and in retinal pigment epithelium. In the retina of teleosts (zebrafish, atlantic cod and roach) melanopsin is expressed in horizontal, amacrine and ganglion cells ${ }^{28,29}$. In the atlantic cod, two melanopsin genes (Opn4a, Opn4b) have been identified, both of which are expressed in cells located in the inner nuclear and ganglion cell layers, while only Opn4a is expressed in horizontal cells. In chicken retina, melanopsin mRNA is expressed in a few dispersed ganglion cells, in cells located in the outer part (bipolar and horizontal cells) and the inner part (amacrine cells) of the inner nuclear layer and in the photorecepors $^{30}$.

In mammals, melanopsin has been described in rodents and primates including humans. In rodents, melanopsin is expressed in a sub-population of neurons in the ganglion and inner nuclear cell layers and in the retinal pigment epithelium 5, 6, 31 . In primates (monkey and human), melanopsin mRNA is expressed in cells within the ganglion cell and the inner nuclear layers ${ }^{15,17}$. In humans, trace expression of melanopsin had been detected in the retinal pigment epithelium, 
which was considered at that time to represent contamination from the retina ${ }^{15}$. Our results however, suggest that the small amount of melanopsin mRNA could originate from cone photoreceptor outer segments which remain in the pigment epithelium during processing. Due to the difficulty to obtain good quality retinal tissue, studies in humans are scarce and none have provided adequate staining of the photoreceptor layer in humans. In addition, the extremely low density coupled with the localisation of label in the outer segment melanopsin positive cones could have been overlooked in previous studies using flat-mounted retinas or human retinas of pathological origin in which almost all of the photoreceptors lacked outer segments 4,17 . Identification of the immunopositive outer segment requires histological retinal sections of high quality which preserves the outer segments intact.

An important finding of our study is the unique expression of melanopsin in human cone outer segments, since co-expression of opsins in other cell types is a common feature in vertebrates including humans. Melanopsin is co-expressed with rod-opsin in Xenopus melanophores ${ }^{32}$, and possibly with pinopsin in chick pinealocytes ${ }^{33}$, or with VA opsin in zebrafish horizontal cells ${ }^{34}$. It is not known whether the chicken photoreceptors which express melanopsin also contain other cone or rod opsins. The cell type and spatial distribution of these chick photoreceptors is also unknown ${ }^{30}$. In rodents, co-localization of two opsin types in single cones is widespread in either part of the cone population ${ }^{35-38}$ or in the entire cone population ${ }^{26}$. In human fetal retinas, cones containing both SW and MW/LW opsins are found early during development and while the number decreases after birth, some coexpression in cones is still present in the adult ${ }^{25}$. Confocal analysis in our study clearly shows the lack of co-expression of melanopsin with other human cone opsins. The finding by Cornish et al. (2004) ${ }^{39}$ of a small population of cones which do not express either SW or MW/LW opsins in human fetal retina may correspond to the immunopositive melanopsin cones described in our study. 
The vertebrate opsins are proteins which use a retinaldehyde chromophore in their photosensory or photoisomerase activity in the visual/irradiance detection cycle. In the photosensory opsins (rod and cone opsins), light is absorbed by the chromophore 11-cis-retinal which is converted to all-trans-retinal. Opsins that act as photoisomerases (e.g. RGR-opsin and peropsin) bind all-trans retinal and use light for conversion to 11-cis-retinal thus supplying photosensory opsins with chromophore. Understanding the biochemical light transduction pathway of melanopsin has been a major challenge, since this opsin-based photopigment had previously been difficult to express in vitro ${ }^{40}$ and had been thought to utilise an invertebrate transduction signalling pathway. This view was also based on the fact that melanopsin was expressed in neuronal cell types located at a distance from the pigment epithelium and thus would not have access to the chromophore retinaldehyde. Recent evidence form several groups show that heterologously expressed melanopsin confers photosensitivity to non-photosensitive cell lines ${ }^{18-20,41}$. In addition, melanopsin is a "bireactive" photopigment with intrinsic photoisomerase activity or functions as a photosensory opsin using 11-cis retinaldehyde as a chromophore. The latter pathway, confirms the possibility that melanopsin can form a functional photopigment in the photoreceptor outer segments of both chicken and human.

Melanopsin contributes to a wide variety of non-visual irradiance detection processes including circadian entrainment, suppression of pineal melatonin synthesis, inhibition of locomotor activity, pupillary constriction, and modulation of sleep-wake states ${ }^{8,9,11-13,42}$. These functions are related to the intrinsic photosensitivity of melanopsin expressing ganglion cells and their projections to structures mediating these processes (SCN, pretectum, IGL, ventrolateral preoptic nucleus and ventral subparaventricular zone) in rodents. In humans, both melanopsin containing ganglion cells and cones may also be involved in mediating these non image forming responses since results of action spectrum and phase shift studies suggest the involvement of a non-rod non-cone 
photopigment ${ }^{43-46}$. In humans, the possible role of melanopsin in non-visual functions has recently been expanded to include functions such as changes in alertness, aspects of autonomic control (thermoregulation and heart rate; ${ }^{47}$ and conceivably modulation of a large-scale network of cortical areas involved in attention processes ${ }^{48}$. In the primate, Dacey et al. (2005) ${ }^{4}$ has also suggested that melanopsin expressing ganglion cells which project to the lateral geniculate nucleus may perhaps convey irradiance information to the visual cortex, a function that could also involve melanopsin containing cones in humans. Furthermore, the suggested non-rod/noncone mechanism that regulates the latency of the b-wave ERG cone response in humans, shows

an action spectrum ${ }^{49} ; \lambda_{\max }=483 \mathrm{~nm}$ ) similar to that of melanopsin containing cells ${ }^{3}$. This response, which has only been demonstrated in humans is suggested to occur presynaptic to second order neurones and thus the melanopsin expressing cone is ideally situated to exert such a modulation of the activity of other cones, possibly through horizontal cell pathways.

\section{Acknowledgments}

This work was supported by grants from CEE QLK6-CT-2002-02258, ACI MNRT, INSERM ACT and Emergence-Rhône-Alpes. We would like to thank I. Provencio for mouse and human melanopsin antiserum and P. Morin, who generously provided human eyes. We thank Wena de Vanssay for skillful technical assistance. 


\section{References}

1. Foster RG, Bellingham J. Inner retinal photoreceptors (IRPs) in mammals and teleost fish. Photochem Photobiol Sci. 2004;3: 617-27.

2. Provencio I, Jiang G, De Grip WJ, Par Hayes W, Rollag MD. Melanopsin: an opsin in melanophores, brain and eye. Proc Natl Acad Sci U S A. 1998;95: 340-345.

3. Berson DM, Dunn FA, Takao M. Phototransduction by retinal ganglion cells that set the circadian clock. Science. 2002;295: 1070-3.

4. Dacey DM, Liao HW, Peterson BB,et al. Melanopsin-expressing ganglion cells in primate retina signal colour and irradiance and project to the LGN. Nature. 2005;433: 749-54.

5. Provencio I, Rollag MD, Castrucci AM. Photoreceptive net in the mammalian retina. Nature. 2002;415: 493.

6. Hattar S, Liao HW, Takao M, Berson DM, Yau KW. Melanopsin-containing retinal ganglion cells: architecture, projections, and intrinsic photosensitivity. Science. 2002;295: 1065-70.

7. Hannibal J, Hindersson P, Knudsen SM, Georg B, Fahrenkrug J. The photopigment melanopsin is exclusively present in pituitary adenylate cyclase-activating polypeptidecontaining retinal ganglion cells of the retinohypothalamic tract. J Neurosci. 2002;22: RC191.

8. Panda S, Sato TK, Castrucci AM,et al. Melanopsin (Opn4) requirement for normal lightinduced circadian phase shifting. Science. 2002;298: 2213-6.

9. Ruby NF, Brennan TJ, Xie X,et al. Role of melanopsin in circadian responses to light. Science. 2002;298: 2211-3. 
10. Dkhissi-Benyahya O, Lupi D, Rieux C,et al. Spectral sensitivity of the hamster circadian system using early gene expression: involvement of classical photopigments. Eur $J$ Neurosci. 2002;017-13.

11. Lucas RJ, Hattar S, Takao M,et al. Diminished pupillary light reflex at high irradiances in melanopsin- knockout mice. Science. 2003;299: 245-7.

12. Hattar S, Lucas RJ, Mrosovsky N,et al. Melanopsin and rod-cone photoreceptive systems account for all major accessory visual functions in mice. Nature. 2003;424: 75-81.

13. Panda S, Provencio I, Tu DC,et al. Melanopsin is required for non-image-forming photic responses in blind mice. Science. 2003;301: 525-7.

14. Belenky MA, Smeraski CA, Provencio I, Sollars PJ, Pickard GE. Melanopsin retinal ganglion cells receive bipolar and amacrine cell synapses. J Comp Neurol. 2003;460: 38093.

15. Provencio I, Rodriguez IR, Jiang G,et al. A novel human opsin in the inner retina. $J$ Neurosci. 2000;20: 600-5.

16. Rollag MD, Berson DM, Provencio I. Melanopsin, ganglion-cell photoreceptors, and mammalian photoentrainment. J Biol Rhythms. 2003;18: 227-34.

17. Hannibal J, Hindersson P, Ostergaard J,et al. Melanopsin is expressed in PACAPcontaining retinal ganglion cells of the human retinohypothalamic tract. Invest Ophthalmol Vis Sci. 2004;45: 4202-9.

18. Qiu X, Kumbalasiri T, Carlson SM,et al. Induction of photosensitivity by heterologous expression of melanopsin. Nature. 2005;

19. Panda S, Nayak SK, Campo B,et al. Illumination of the melanopsin signaling pathway. Science. 2005;307: 600-4. 
20. Melyan Z, Tarttelin EE, Bellingham J, Lucas RJ, Hankins MW. Addition of human melanopsin renders mammalian cells photoresponsive. Nature. 2005;

21. Lucas RJ, Douglas RH, Foster RG. Characterization of an ocular photopigment capable of driving pupillary constriction in mice. Nat Neurosci. 2001;4: 621-6.

22. Szel A, Rohlich P. The mosaic of colour-specific photoreceptors in the mammalian retina as defined by immunocytochemistry. Acta Morphol Hung. 1988;36: 191-202.

23. Curcio CA, Allen KA, Sloan KR,et al. Distribution and morphology of human cone photoreceptors stained with anti-blue opsin. J Comp Neurol. 1991;312: 610-24.

24. Curcio CA, Sloan KR, Kalina RE, Hendrickson AE. Human photoreceptor topography. J Comp Neurol. 1990;292: 497-523.

25. Xiao M, Hendrickson A. Spatial and temporal expression of short, long/medium, or both opsins in human fetal cones. J Comp Neurol. 2000;425: 545-59.

26. Lukats A, Dkhissi-Benyahya O, Szepessy Z,et al. Visual pigment coexpression in all cones of two rodents, the Siberian hamster, and the pouched mouse. Invest Ophthalmol Vis Sci. 2002;43: 2468-73.

27. Chiquet C, Dkhissi-Benyahya O, Chounlamountri N,et al. Characterization of calbindinpositive cones in primates. Neuroscience. 2002;115: 1323-33.

28. Bellingham J, Whitmore D, Philp AR, Wells DJ, Foster RG. Zebrafish melanopsin: isolation, tissue localisation and phylogenetic position. Brain Res Mol Brain Res. 2002;107: 128-36.

29. Drivenes O, Soviknes AM, Ebbesson LO,et al. Isolation and characterization of two teleost melanopsin genes and their differential expression within the inner retina and brain. J Comp Neurol. 2003;456: 84-93. 
30. Chaurasia SS, Rollag MD, Jiang G,et al. Molecular cloning, localization and circadian expression of chicken melanopsin (Opn4): differential regulation of expression in pineal and retinal cell types. J Neurochem. 2005;92: 158-70.

31. Peirson SN, Bovee-Geurts PH, Lupi D,et al. Expression of the candidate circadian photopigment melanopsin (Opn4) in the mouse retinal pigment epithelium. Brain Res Mol Brain Res. 2004;123: 132-5.

32. Miyashita Y, Moriya T, Yamada K,et al. The photoreceptor molecules in Xenopsu tadpole tail fin, in which melanophores exist. Zool Sci. 2001;18: 671-674.

33. Okano T, Yoshizawa T, Fukada Y. Pinopsin is a chicken pineal photoreceptive molecule. Nature. 1994;372: 94-7.

34. Kojima D, Mano H, Fukada Y. Vertebrate ancient-long opsin: a green-sensitive photoreceptive molecule present in zebrafish deep brain and retinal horizontal cells. $J$ Neurosci. 2000;20: 2845-51.

35. Rohlich P, van Veen T, Szel A. Two different visual pigments in one retinal cone cell. Neuron. 1994;13: 1159-1166.

36. Szel A, Lukats A, Fekete T,et al. Visual pigment coexpression in cone cells. Med Sci Monit. 1998;4: 46-56.

37. Applebury ML, Antoch MP, Baxter LC,et al. The murine cone photoreceptor: a single cone type expresses both S and M opsins with retinal spatial patterning. Neuron. 2000;27: $513-23$.

38. Parry JW, Bowmaker JK. Visual pigment coexpression in Guinea pig cones: a microspectrophotometric study. Invest Ophthalmol Vis Sci. 2002;43: 1662-5. 
39. Cornish EE, Xiao M, Yang Z, Provis JM, Hendrickson AE. The role of opsin expression and apoptosis in determination of cone types in human retina. Exp Eye Res. 2004;78: 1143-54.

40. Newman LA, Walker MT, Brown RL, Cronin TW, Robinson PR. Melanopsin forms a functional short-wavelength photopigment. Biochemistry. 2003;42: 12734-8.

41. Isoldi MC, Rollag MD, de Lauro Castrucci AM, Provencio I. Rhabdomeric phototransduction initiated by the vertebrate photopigment melanopsin. Proc Natl Acad Sci U S A. 2005;102: 1217-21.

42. Gooley JJ, Lu J, Fischer D, Saper CB. A broad role for melanopsin in nonvisual photoreception. J Neurosci. 2003;23: 7093-106.

43. Brainard GC, Hanifin JP, Greeson JM,et al. Action spectrum for melatonin regulation in humans: evidence for a novel circadian photoreceptor. J Neurosci. 2001;21: 6405-12.

44. Thapan K, Arendt J, Skene DJ. An action spectrum for melatonin suppression: evidence for a novel non- rod, non-cone photoreceptor system in humans. J Physiol. 2001;535: 261-7.

45. Lockley SW, Brainard GC, Czeisler CA. High sensitivity of the human circadian melatonin rhythm to resetting by short wavelength light. J Clin Endocrinol Metab. 2003;88: 4502-5.

46. Cooper HM, Chiquet C, Gronfier C,et al. Midwavelength monochromatic light is more effective for suppressing plasma melatonin in humans than broadband white light. Invest Ophthalmol Vis Sci. 2004;45: ARVO E-Abstract 4345.

47. Cajochen C, Munch M, Kobialka S,et al. High sensitivity of human melatonin, alertness, thermoregulation and heart rate to short wavelength light. J Clin Endocrinol Metab. 2004; 
48. Perrin F, Peigneux P, Fuchs S,et al. Nonvisual responses to light exposure in the human brain during the circadian night. Curr Biol. 2004;14: 1842-6.

49. Hankins MW, Lucas RJ. The primary visual pathway in humans is regulated according to long- term light exposure through the action of a nonclassical photopigment. Curr Biol. 2002;12: 191-8. 


\section{Figure legends}

Figure 1. Melanopsin expression in the human retina. (A) Melanopsin is found in a subset of cells located in the ganglion cell layer and (B) in the inner nuclear layer (anti-human melanopsin). These melanopsin-expressing cells have large somas $(15-20 \mu \mathrm{m})$ and show strongly staineddendrites located at the INL-IPL and IPL-GCL borders (scale $=20 \mu \mathrm{m}$ ). Melanopsin expressing cones are detected with both antibodies against human (C) and mouse (D) melanopsin. These melanopsin expressing cones are extremely rare and are only observed in peripheral regions of the retina, from the parafoveal region up to roughly $2 \mathrm{~mm}$ of the ora serrata. The density of melanopsin containing cones is estimated at $5-25$ cones $/ \mathrm{mm}^{2}$, corresponding to about $5 \%$ of the SW cone population density (scale $=20 \mu \mathrm{m})$. OPL, outer plexiform layer; ONL, outer nuclear layer; IPL, inner plexiform layer; INL, inner nuclear layer; GCL, ganglion cell layer.

Figure 2. Confocal images of a transverse immunostained human retinal section showing localisation of fluorescent PNA-lectin (left) and anti-melanopsin label (MEL, middle). The separate images (left and middle) and the overlayed color image (right, melanopsin in yellow and PNA in green fluorescence) clearly show that melanopsin positive photoreceptors are labelled by PNA demonstrating that melanopsin positive photoreceptors are cones (scale in bottom right $=20$ $\mu \mathrm{m})$.

Figure 3. Characterisation of melanopsin-positives cones showing the absence of co-expression with other cone opsins. (A) This panel illustrates a series of confocal images of cones immunostained for MW/LW opsins (left), melanopsin (MEL, middle) and the overlayed color 
image (right). (B) Panel showing confocal images of cones immunostained for SW opsin (left), melanopsin (MEL, middle) and the overlayed color image (right). In the color overlays in A and B the melanopsin cones (red fluorescence) are distinct from the SW or MW/LW cones shown in green fluorescence (scale in bottom right $=20 \mu \mathrm{m}$ ). 
Figure 1

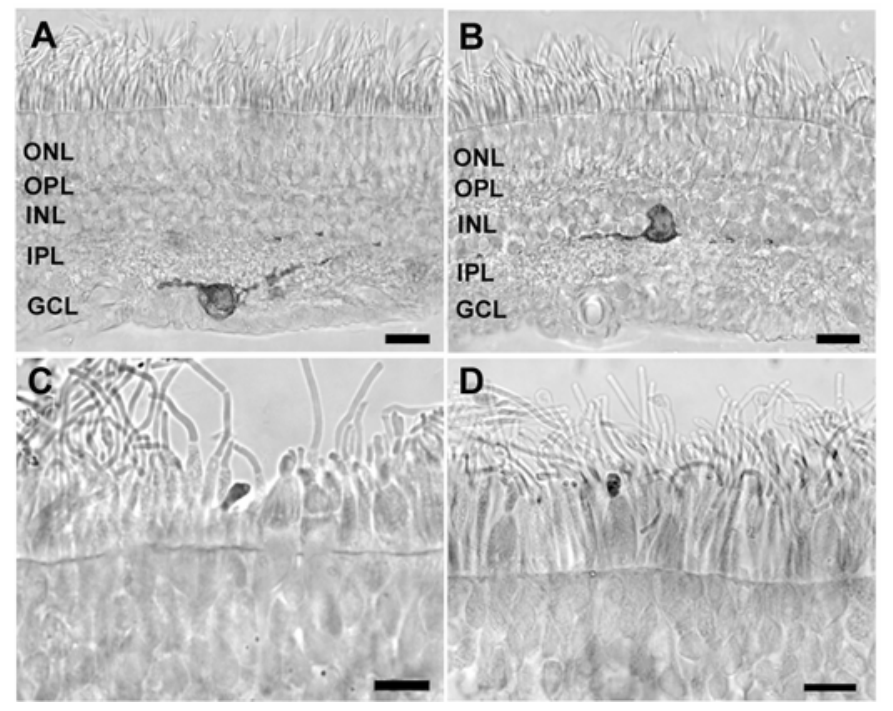


Figure 2

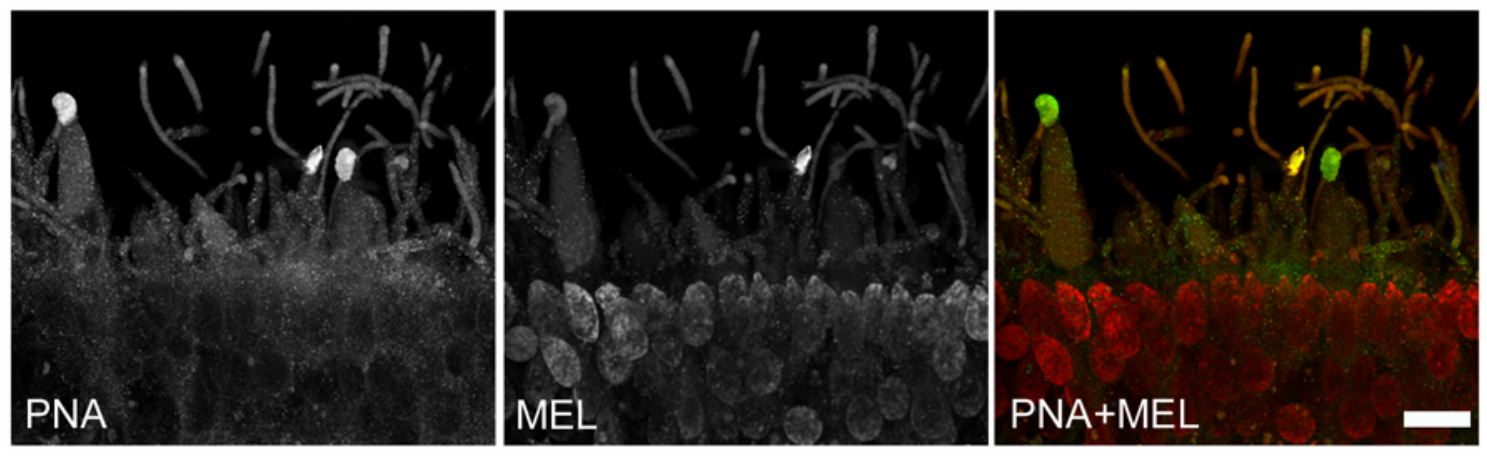


Figure 3

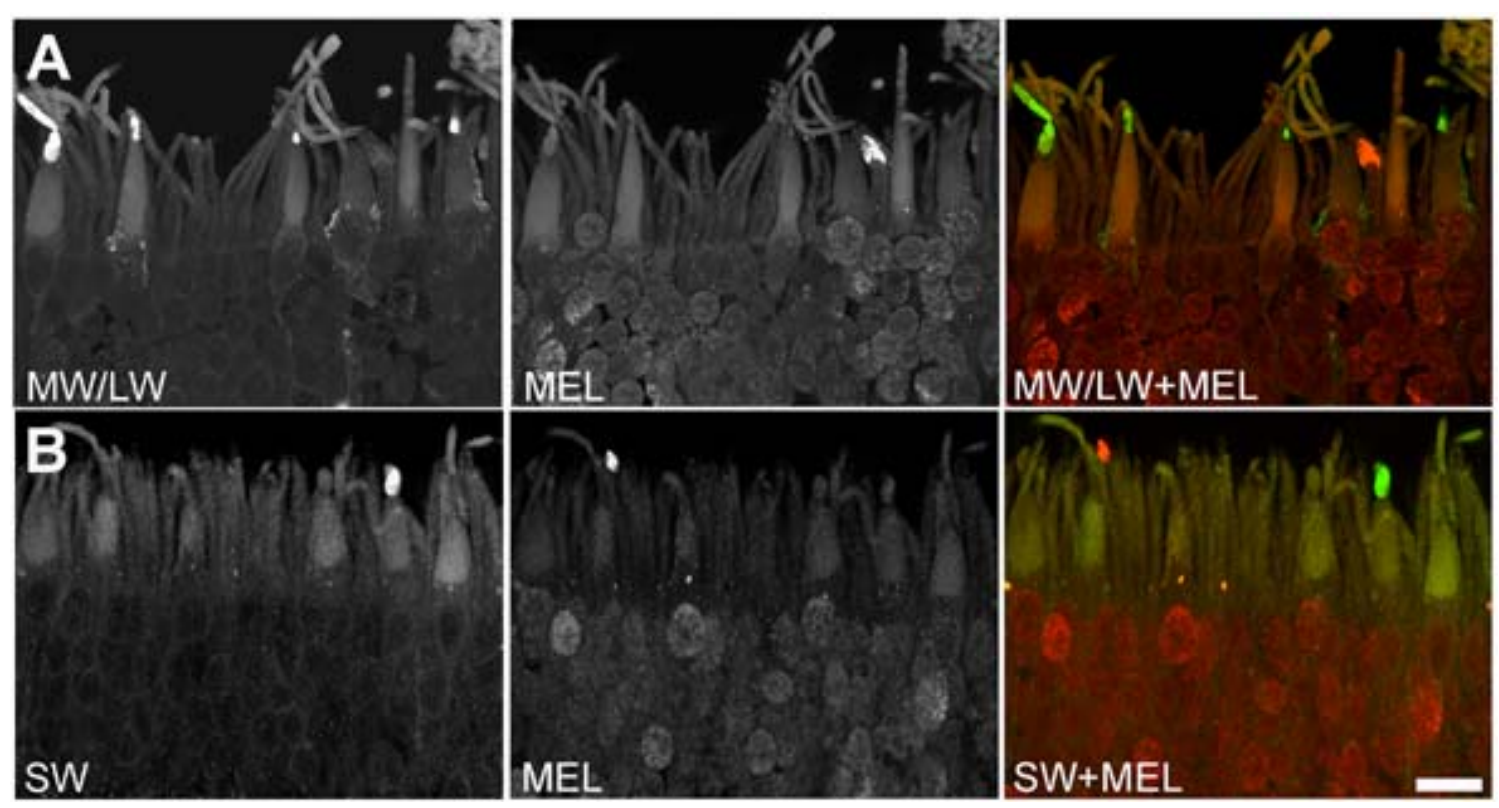

